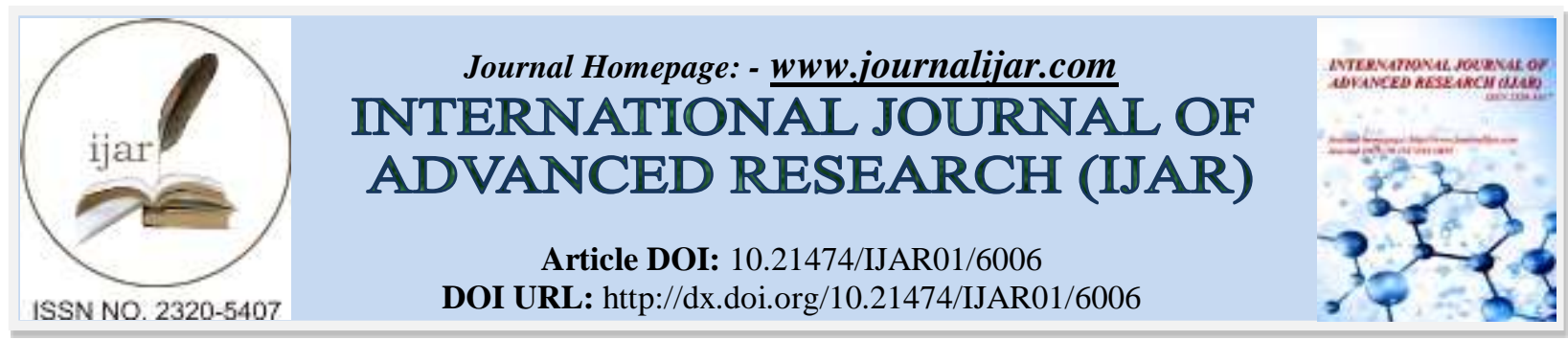

RESEARCH ARTICLE

\title{
A CASE REPORT OF PROLONGED APNEA DURING ECT IN A PATIENT WITH SUICIDAL ATTEMPT BY ORGANOPHOSPHORUS POISON.
}

\section{Dr. Pallavi Deulkar ${ }^{1}$ and Dr. Karuna Taksande ${ }^{2}$.}

1. PG student, Department of Anesthesia, Datta Meghe Institute of Medical Science, Sawangi (Meghe), Wardha.

2. Associate professor, Department of Anesthesia, Datta Meghe Institute of Medical Science, Sawangi (Meghe), Wardha.

\section{Manuscript Info}

\section{Manuscript History}

Received: 08 October 2017

Final Accepted: 10 November 2017

Published: December 2017

Key words:-

Organophosphorus Poison,Suicidal

Attempt,ECT,succinylcholine,Prolonged Apnea.

\section{Abstract}

Introduction: Organophosphorus pesticides have been used in some cases for suicidal attempts. Such poison can affect plasma cholinesterase activity.

Methods: This case was a 43-year-old man hospitalized due to suicide attempt with swallowing agricultural poison. The patient, diagnosed with major depressive disorder (MDD), underwent treatment with electroconvulsive therapy (ECT). At the first ECT session, the patient developed apnea for 4 hours after receiving $25 \mathrm{mg}$ succinylcholine.

Results: The patient was intubated and kept on ventilator support for 4 hrs in ICU; after restoration of respiration depth and rate, the patient was extubated.

Conclusion: Collectively, in cases with history of suicide attempts, taking organophosphorus pesticides should be warned for pre-ECT anesthesia.

Copy Right, IJAR, 2017,. All rights reserved.

\section{Introduction:-}

1. Electroconvulsive therapy (ECT) is standard practice for psychiatric patients with suicidal tendencies.

2. The objective of anesthesia is to provide a rapid onset and offset of both unconsciousness and muscle relaxation for the duration of electrical stimulus and subsequent seizure.

3. Succinylcholine $(0.5 \mathrm{mg} / \mathrm{kg})$ owing to its short duration neuromuscular blocking agent, is used to decrease the risk of serious injury.

4. Organophosphorous, which is used as an common insecticide, its poisoning is an important cause for prolonged apnea following Succinylcholine.

5. We report a case of prolonged apnea following organophosphorus poisoning, which was not revealed to treating doctors.

\section{Case report:-}

1. A 43 year old male, who was an illiterate laborer, came to psychiatry ward, AVBRH, Sawangi, where he was planned for intermittent modified ECT treatment, as he was diagnosed with Major Depressive Disorder (MDD) and he was on medication tab. Olanzapine.

2. Previously he was hospitalized at Sewagram, Wardha for Organophosphorus poisoning which he had taken 20 days prior. 


\section{Case management:-}

1. An informed written consent was obtained from the patient and the attender. fasting status was confirmed.

2. Monitors were connected.

3. Preoxygenation done with $100 \%$ of oxygen.

4. Inj Glycopyrrolate $0.2 \mathrm{mg}$ was given.

5. Patient induced with inj Propofol $100 \mathrm{mg}$, ventilation checked and inj succinylcholine $25 \mathrm{mg}$ was given.

6. The patient was ventilated for 30 seconds with bains circuit, then mouth gag was inserted and ECT was given.

7. After procedure the patient was ventilated for 45 minutes.

8. Since the patient did not regain spontaneous respiration he underwent orotracheal intubation with 8.0 Cuffed ET Tube, air entry was checked and tube fixed.

9. On repeated questioning, attenders revealed that 20 days back, patient consumed unknown quantity of organophosphate.

10. Patient was catherized and input, output was monitored and inj Lasix 10mg was given.

11. Hydrocortisone $100 \mathrm{mg}$ was given to prevent laryngeal edema.

12. The patient was then shifted to ICU for 4 hours and after restoration of respiration depth and rate, adequate tidal volume and good muscle tone, and recovery of consciousness and reflexes, and a normal ABG, the patient was extubated.

13. Patient was observed with a multichannel monitor for $24 \mathrm{hrs}$ and then was sent to the ward.

\section{Conclusion:-}

1. A case of depression with a failed attempt of suicide with Organophosphorus agriculture toxin, was given modified ECT using low-dose Suxamethonium.

2. Apnea following Suxamethonium was prolonged due to recent intake of organophosphate poisoning, which was concealed by attenders.

It is imperative to take detailed history including drug history to avoid such recurrences.

\section{References:-}

1. Hall AH, Rumack BH. Incidence, presentation and therapeutic attitudes to ant cholinesterase poisoning in the USA. In: Ballantyne B, Marrs TC, editors. Clinical and experimental toxicology of organophosphates and garbamates. Oxford, England: Butterworth-Heinemann; 1992.

2. Marrs TC. Organophosphate poisoning. Pharmacol Ther. 1993;58:51-66. [PubMed: 8415873]

3. Senanayake N, Karalliedde L. Neurotoxic effects of Organophosphate insecticides: An intermediate syndrome. N Engl J Med. 1987;316:761- [PubMed: 3029588]. 